\title{
Results of single-stage acetabulum reconstruction and total hip arthroplasty in the management of pelvic discontinuity caused by ununited acetabulum fracture
}

\author{
Dharmendra Kumar ${ }^{1}$, Narendra Singh Kushwaha ${ }^{2, *}$, Yashwardhan Jaiswal ${ }^{3}$, Amit Singh ${ }^{4}$, Vineet Sharma ${ }^{5}$ \\ ${ }^{\mathbf{1}}$ Assistant Professor, ${ }^{\mathbf{2}}$ Associate Professor, ${ }^{\mathbf{3}, 4}$ Senior Resident, ${ }^{5}$ Professor, Dept. of Orthopaedic Surgery, King George Medical \\ University, Lucknow, Uttar Pradesh, India
}

*Corresponding Author: Narendra Singh Kushwaha

Email: orthosurgeon.narendra2007@gmail.com

\begin{abstract}
Introduction: Non-union of acetabulum fracture is a common occurrence in developing countries. Pelvic discontinuity due to ununited fracture acetabulum poses a serious challenge in the management of the patient. Results of ORIF of these fractures are not promising due to various reasons. We aim to present results on single-stage acetabulum reconstruction and total hip arthroplasty, the literature on which is lacking.

Materials and Methods: We prospectively studied the outcome of single-stage acetabulum reconstruction and total hip arthroplasty in patients with pelvic discontinuity caused by ununited fracture acetabulum of more than 3 months duration. From March 2015 to December 2018, 11patients (7 males, 4 females, average age 42 years) were treated in our hospital. All cases underwent open reduction internal fixation with posterior column plate, impaction bone grafting, uncemented porous coated hemispherical acetabulum cup hip arthroplasty.

Results: Union of the columns was achieved in all the cases with 7 patients (63.6\%) showed union at 12 months and rest 4 patients (36.4\%) took 18 months to unite. At final follow up, mean Harris hip score improved from 54.2 points (range 24-63) to 91.4 points (range 79-95). One superficial surgical site infection and one heterotopic ossification was noted in our study which had no sequel on clinical outcome at their last follow up.

Conclusion: Single stage acetabulum reconstruction by posterior column plating with impaction bone grafting and uncemented porous coated hemispherical acetabulum cup hip arthroplasty is a genuine option in management of pelvic discontinuity caused by ununited fracture of acetabulum.
\end{abstract}

Keywords: Neglected fracture acetabulum, Ununited fracture acetabulum, Pelvic discontinuity, Acetabulum reconstruction, Single stage acetabulum reconstruction.

\section{Introduction}

Acetabulum fracture going into non-union is very commonly encountered in developing countries as most of the fractures are either neglected or treated conservatively that may land up in non-union. ${ }^{1,2}$

Open reduction and internal fixation of these fractures are associated with difficult mobilization of caudal fragment due to scarring between fragments and results are not promising because of repeated indentation of head, achieving acceptable reduction, abnormal callus formation and chondral changes. ${ }^{3}$

Total hip arthroplasty is a reliable option for these neglected, ununited fractures but there are problems like non-union of column fracture, medial displacement and rotation of caudal fragment making total hip arthroplasty difficult. So, the question which comes in mind is that whether osteosynthesis is to be done simultaneously with total hip arthroplasty or osteosynthesis is to be performed first to ensure healing of the column followed by total hip arthroplasty because stability of the cup is dependent on integrity of column.

Two stage management of pelvic discontinuity associated with total hip arthroplasty is well described in the literature. ${ }^{4}$ Also, studies on single stage management of acute acetabulum fracture by acetabulum reconstruction and total hip arthroplasty are present ${ }^{5}$ but literature on single stage management of pelvic discontinuity caused by ununited fracture acetabulum are lacking.

We aim to present our results of single stage management of pelvic discontinuity caused by ununited fracture acetabulum by acetabulum reconstruction and total hip arthroplasty.

\section{Materials and Methods}

This is a prospective study done in King George Medical University, Lucknow from March 2015 to December 2017. Eleven patients of pelvic discontinuity caused by ununited fracture acetabulum of more than 3 months duration were included in this study after taking due clearance from ethical committee from university. Pelvic discontinuity associated with revision hip replacement surgery, mal-united acetabulum fractures, previously treated failed acetabulum fractures and iatrogenic injury were excluded from the study.

Pre-operatively $\mathrm{x}$-rays of pelvis and Judet views and CT scan with 3D reconstruction were obtained in all patients. Basic haematological investigations were done to rule out infection.

After all aseptic preparation, patient was positioned in lateral position. Standard postero-lateral approach was used. Haemostasis was achieved. Standard femoral neck osteotomy was done. Exposure of the acetabulum was done to assess the fracture and the bony defect. Fracture sites were curetted from inside the acetabulum 
including anterior column, posterior column and quadrilateral plate. At this point, discontinuity between the superior and caudal fragments assessed and record was made of the stability of the columns. Posterior column of acetabulum was exposed by putting bone levers in sciatic notches while maintaining hip extension and knee flexion to avoid sciatic nerve injury. Thereafter, caudal fragment was mobilized with the help of Schanz screw in the ischial tuberosity and posterior column was reduced at its best possible position. Reduction was temporally fixed with k-wires and inter-fragmentary screws were applied wherever applicable. Reduction was supported by posterior column plate extending from ischial tuberosity to supraacetabular region. 2-3 cortical screws were used in distal as well as proximal fragments. According to bone defect in the acetabular socket, bone graft was prepared from femoral head. Using transverse acetabular ligament as the landmark, serial reaming of the acetabulum was done. Acetabulum was under-reamed deliberately and the defect was re-assessed. Bone graft applied over the defect and impaction grafting was done in all cases using reverse reaming. Posterior column fracture site was also grafted from outside the acetabulum.

Trial of the acetabulum cup was done according to the last size reamer. Stability was assessed and final component of the acetabulum of same size was applied. Implant in all the cases used was hemispherical porous coated acetabulum cup to avoid sinking of the cup. We took superior acetabular dome as a reference to avoid medial mal-placement of the cup because the caudal fragment was already medially displaced in most of the cases. Cup was fixed with 2-3 screws into the intact Ilium and posterior column. Standard cemented or uncemented femoral stem was applied. $36 \mathrm{~mm}$ femoral head was used. Thereafter, hip joint stability was assessed and closure was done in layers with drain.

Antibiotic was given 30 minutes before the incision. Post-operatively 5 days of IV antibiotics were given following which oral antibiotics till stitch removal. In-bed mobilization exercises were done for 6 weeks. Partial weight bearing was allowed at 6 weeks. Full weight bearing started according to discontinuity healing. Post operatively x-rays of pelvis and Judet views were done to see radiological union and possible complication. Functional status were assessed by Harris Hip Score at each follow up visit. Follow up was done at $6 \mathrm{wks}, 12 \mathrm{wks}, 24 \mathrm{wks}$ and thereafter on six monthly basis.

\section{Results}

Eleven patients were operated upon during the study. Patient characteristics are depicted in Table 1. Two patients had associated ipsilateral shaft of femur fracture for which closed reduction internal fixation with intramedullary interlocking nail was performed at the time of trauma. No patient was lost to follow up in this series.

Radiological results at last follow up and by comparing serial radiographs showed that all the cases had union as well as well-fixed implant without evidences of loosening or mal-orientation. Migration of cup was present in one patient, although the patient was asymptomatic and implant was well-fixed as depicted in Fig. 1. Nine out of the 11 grafts (impaction grafting) showed union at three months and they had become structurally integrated with the parent bone, as evidenced by the trabecular reorientation on serial radiographs. Rest 2 grafts showed union at six months post-operatively. Union of the columns took longer time in our study with 7 patients $(63.6 \%)$ showed union at 12 months and rest 4 patients (36.4\%) took 18 months to unite. Fig. 2 shows union of column at 1year with the patient's functional status.

Mean Harris hip score (HHS) improved from 54.2 points (range 24-63) to 91.4 points (range 79-95) which was statistically significant $(\mathrm{p}<0.05)$.

Superficial surgical site infection was seen in one patient which was treated with local debridement and IV antibiotics. Heterotopic ossification (HO) was present in one hip $(9.1 \%)$ where excessive periosteal stripping was done due to comminuted posterior wall fragment. However, this had no sequel on the final clinical outcome. No dislocation, neurological complications or deep venous thrombosis was noticed during the follow up.

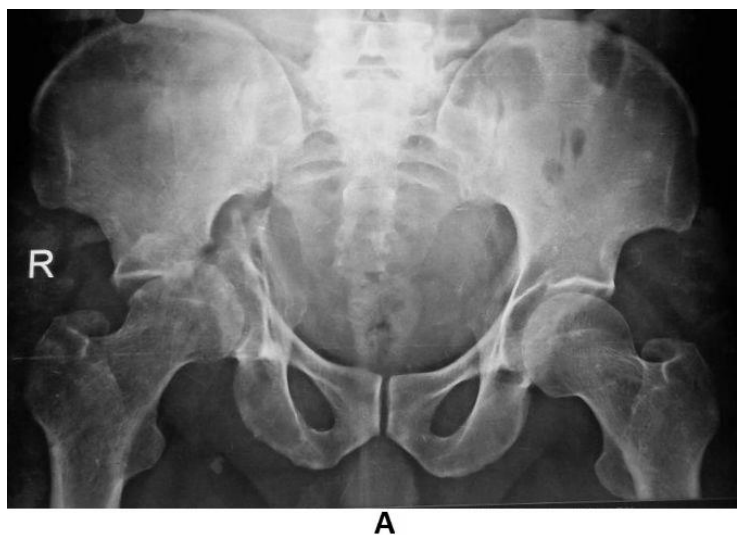

Fig. 1A: Pre-operative AP radiograph of ununited transverse with posterior wall acetabulum fracture. 


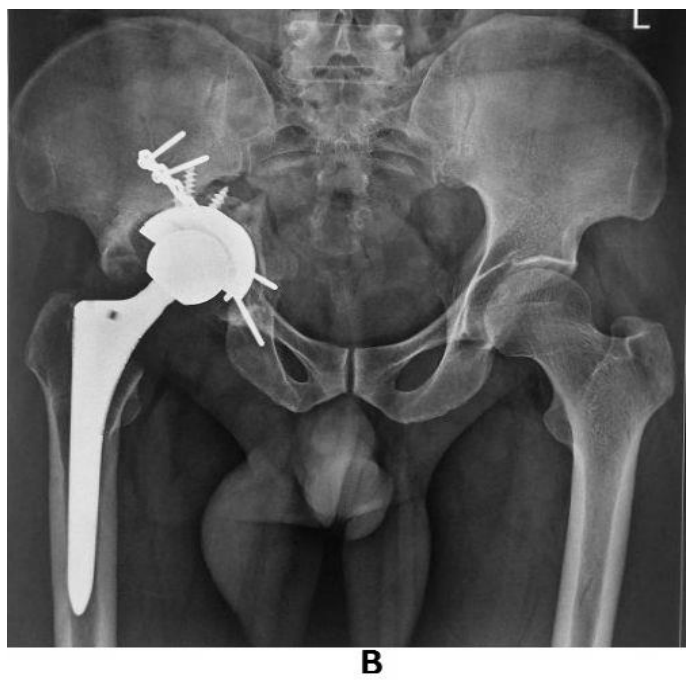

Fig. 1B: Post-operative radiograph at 6 months

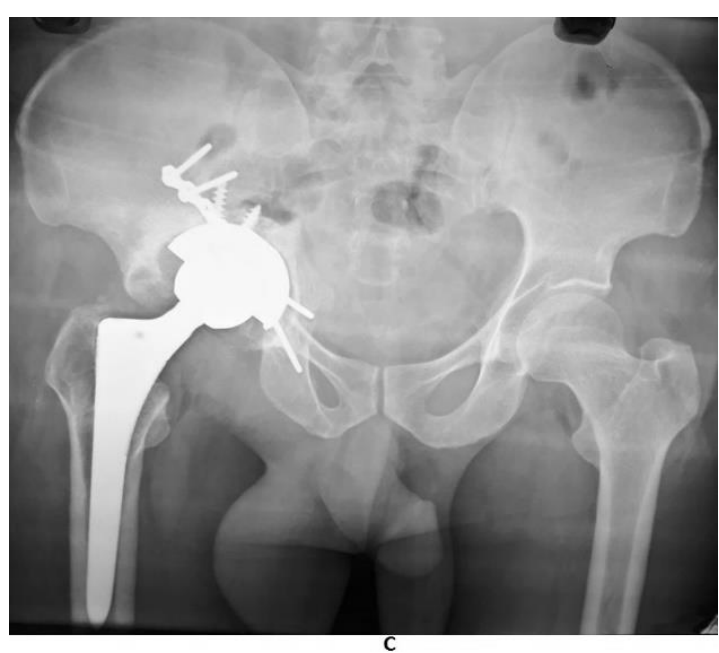

Fig. 1C: Post-operative radiograph at 2 years showing discontinuity healing and consolidation of impaction graft. Migration of cup is seen without affecting the stability.

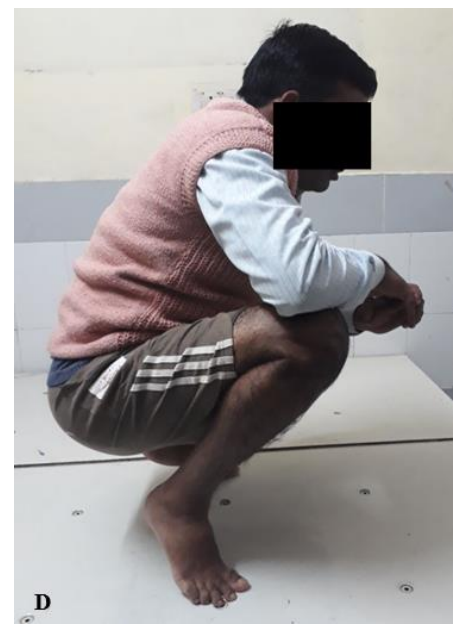

Fig. 1D: Functional status of the patient. Patient had Sciatic nerve palsy pre-operatively which partially recovered during the follow up

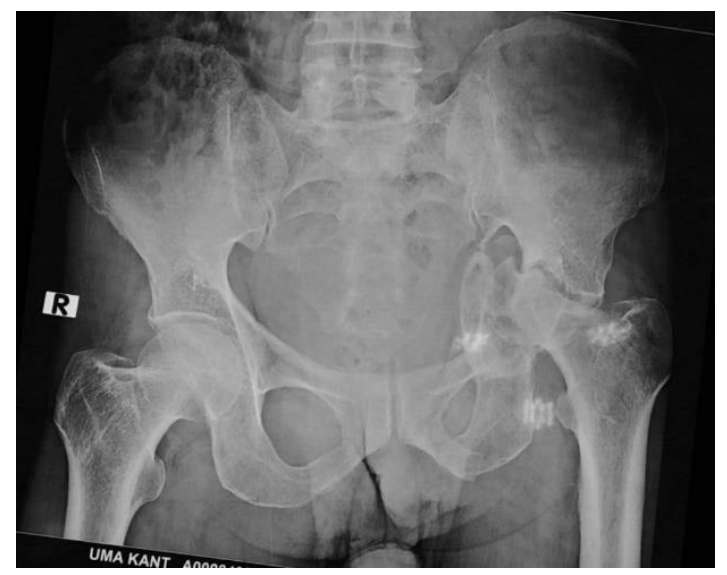

Fig. 2A: Pre-operative AP radiograph of ununited transverse acetabulum fracture.

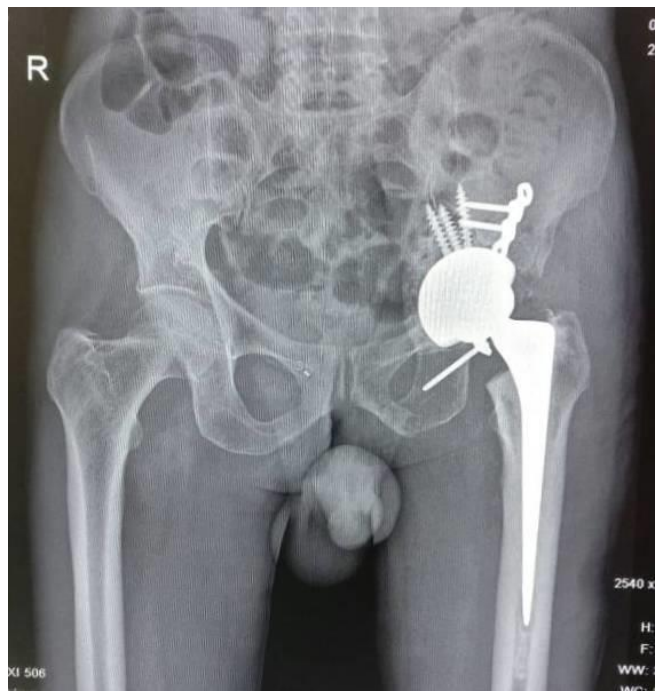

Fig. 2B: Post-operative AP radiograph at 6 months.

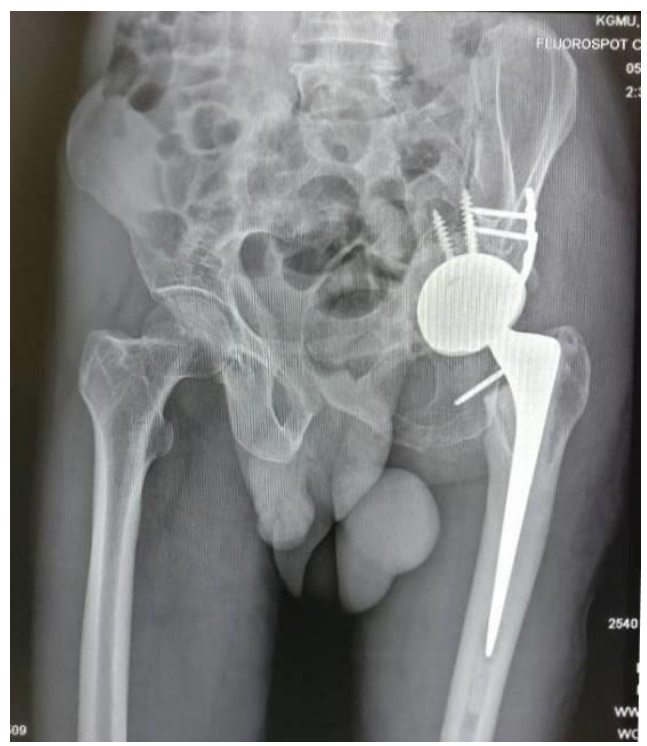

Fig. 2C: Post-operative obturator view radiograph at 6 months 


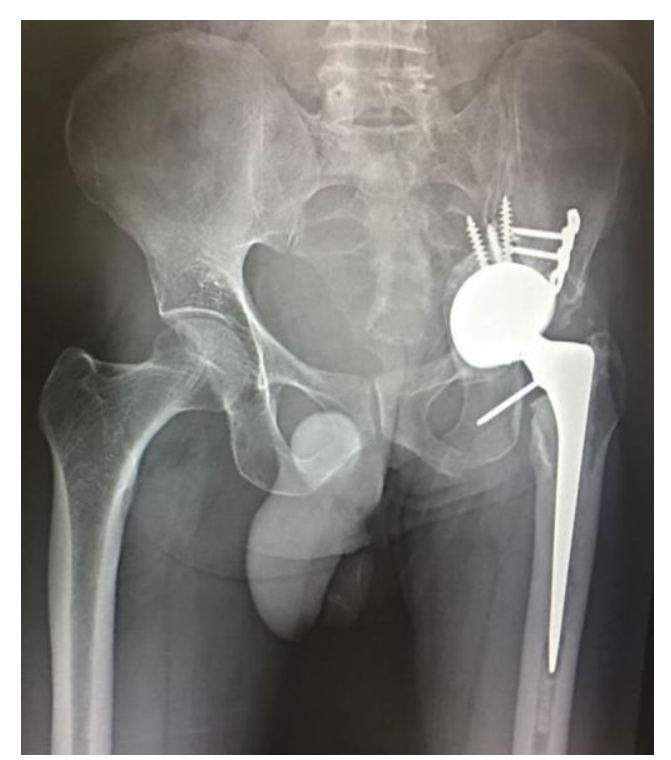

Fig. 2D: Post-operative radiograph at 1 year showing of discontinuity healing with stable cup
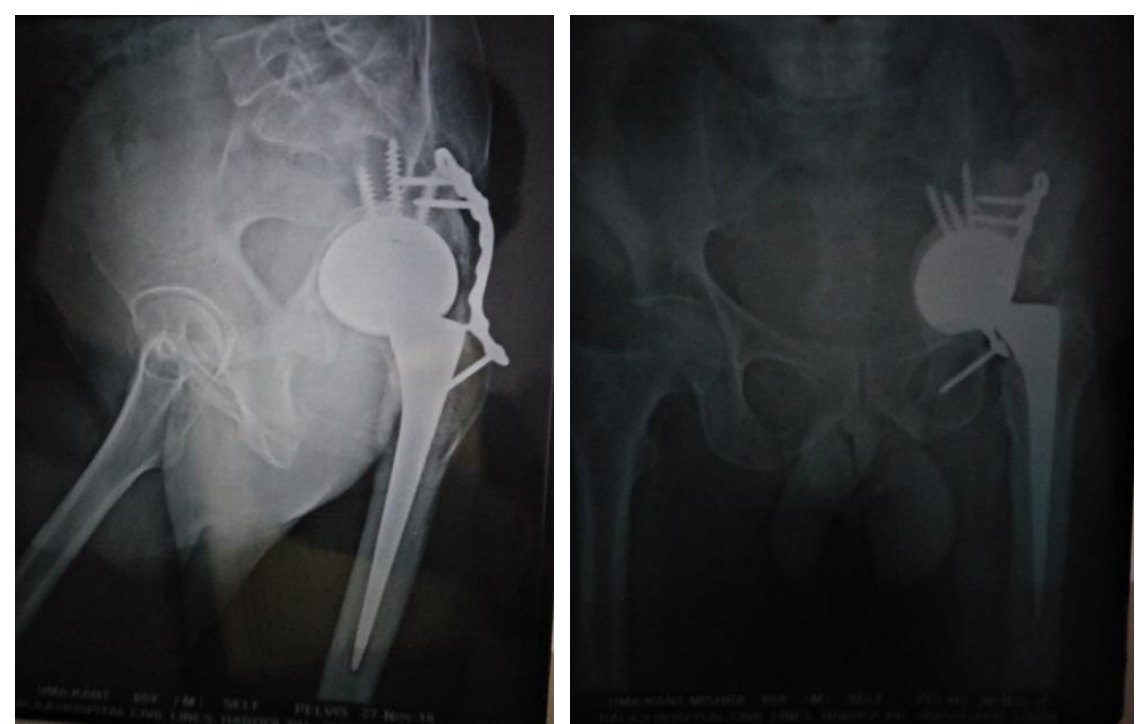

Fig. 2E,F: Post-operative radiograph at 2 year showing complete healing of fracture and stable implant

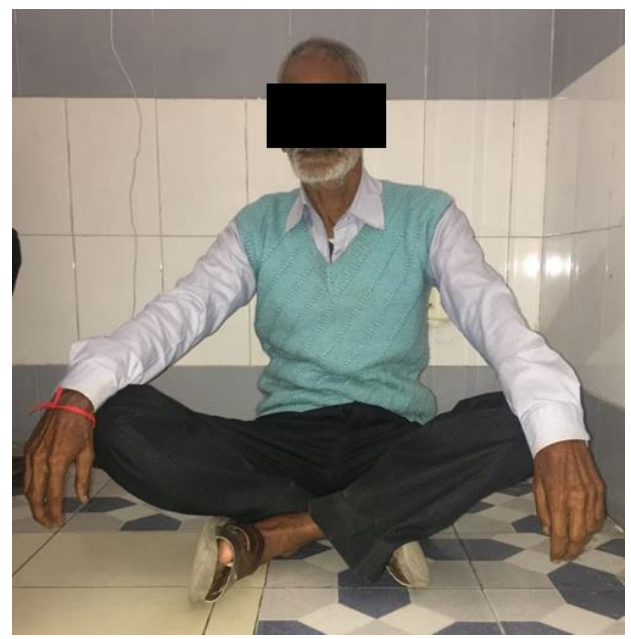

Fig. 2G: Functional status of the patient showing sitting cross-legged 
Table 1: Patient demographics

\begin{tabular}{|c|c|}
\hline No. of Hips & 11 \\
\hline \multicolumn{2}{|c|}{ Age at the time of operation (years) } \\
\hline Mean & 42 \\
\hline Range & $26-53$ \\
\hline \multicolumn{2}{|l|}{42} \\
\hline $26-53$ & 7 \\
\hline Female & 4 \\
\hline \multicolumn{2}{|l|}{ Mode of trauma } \\
\hline Motor vehicle accident & 10 \\
\hline Fall from height & 1 \\
\hline \multicolumn{2}{|l|}{ Fracture pattern } \\
\hline Transverse & 6 \\
\hline T-type & 3 \\
\hline Transverse with posterior wall & 2 \\
\hline \multicolumn{2}{|c|}{ Time duration between the injury and the management (months) } \\
\hline Mean & 5 \\
\hline Range & $3-12$ \\
\hline \multicolumn{2}{|l|}{ Duration of follow up (months) } \\
\hline Mean & 15 \\
\hline Range & $12-36$ \\
\hline
\end{tabular}

\section{Discussion}

Recently, hip joint replacement has been advocated in many studies in acute acetabulum fractures especially in elderly patients with impaction of femoral head or comminution of dome where high chance of failure of open reduction and fixation is present. ${ }^{6,7}$ Total hip arthroplasty in fractures of acetabulum does not produce same results as in case of arthritis of hip joint from other causes because of complexity regarding bone defects, bony irregularities, mal-union or nonunion of acetabular fractures. ${ }^{8}$

Pelvic discontinuity caused by ununited fracture acetabulum has many challenges while planning for total hip arthroplasty as integrity of column is utmost important for survival of arthroplasty. Reduction and maintenance of fragments till union is one problem. Also, to provide adequate contact between acetabular cup and host bone is a challenging task. Many techniques like plating of columns with acetabular cup implantation, ${ }^{9}$ cup cage construct, ${ }^{10}$ jumbo cup and rings, ${ }^{11}$ custom triflange cup ${ }^{12}$ and distraction methods ${ }^{13}$ are described in literature to treat pelvic discontinuity due to various etiology. Pelvic discontinuity is most commonly encountered in revision hip surgeries. Other causes are traumatic and sometimes iatrogenic during uncemented cup implantation. Each techniques has its own indications and complications but in general when stability of the cup is provided by the acetabulum component itself by cages or rings, it has more chances of implant failures due to problems of osteo-integration.

In our study, we have tried to be more biological by doing reduction of posterior column as much as possible and applied compression plate on it. Acetabulum defect was assessed and according to its morphology graft was prepared from femoral head.
Defect was grafted followed by impaction grafting. Impaction bone grafting has crucial role not only in providing biological environment for acetabulum cup osteo-integration but also causes union of fractures. This has been supported by many studies. ${ }^{14,15}$

The shortcoming of our technique is that if the fracture fails to unite then it will lead to failure of acetabulum cup. So, the question arises that is it worth to do open reduction internal fixation and total hip arthroplasty in a single stage or go first for healing of fracture then proceed for total hip replacement in second stage.

Two stage treatment of old or neglected ununited acetabulum fracture has the burden of dual surgery, require more blood transfusion and difficult second surgery due to lot of fibrosis and scarring. Two stage treatments reserved for osteoporotic patients with pelvic discontinuity caused by revision hip surgery in which first stage reconstruction of acetabulum with plate and bone grafting followed by total hip arthroplasty in second stage. Biology of such patients is not favourable for single stage management due to bone defect because of osteolysis and decreased healing potential of the discontinuity. ${ }^{4}$

In our study $63.6 \%$ of patients were united in 12 months. Rest $36.4 \%$ patients had delayed union who had taken 18 months to unite. Comparing with studies on pelvic discontinuity associated with revision hip treated by various methods Berry et $\mathrm{al}^{16}$ found union in $71 \%$ of cases, Tauton et $\mathrm{al}^{12}$ found union in $81 \%$, Eggli et $\mathrm{al}^{11}$ found union in $100 \%$ of cases as depicted in Table 2.

The mean Harris Hip Score at final follow up in our study was 93.1 as compared to 74.8 in Tauton et al 
while Eggli et al found 73.1. Berry et al found $60 \%$ satisfactory rate.

We have not revised any hip due to any cause in our study while Berry et al revised $33 \%$ in his study, Tauton et al revised 30\% in his study and Eggli et al revised $14.3 \%$ in his study.

Limitation of our study is that sample size is limited. Also, the mean follow up period is not sufficient to comment on the final outcome, functional status, revision rate and possible long term complications. Most importantly, there is no study on ununited fracture acetabulum causing pelvic discontinuity available in literature for comparing our results for planning future cases of similar nature.

Table 2: Results of various studies

\begin{tabular}{|c|c|c|c|c|c|c|c|}
\hline Study & $\begin{array}{l}\text { Primary } \\
\text { pathology }\end{array}$ & Procedure & $\begin{array}{l}\text { No. of } \\
\text { hips }\end{array}$ & $\begin{array}{c}\text { Union of } \\
\text { discontinuity } \\
(\%)\end{array}$ & $\begin{array}{c}\text { Functional } \\
\text { status } \\
\text { (HHS) }\end{array}$ & $\begin{array}{c}\text { Revision rate } \\
(\%)\end{array}$ & $\begin{array}{c}\text { Follow } \\
\text { up (year) }\end{array}$ \\
\hline $\begin{array}{l}\text { Rogers et } \\
\mathrm{al}^{9}\end{array}$ & $\begin{array}{c}\text { Acute PD } \\
\text { Revision hip }\end{array}$ & $\begin{array}{c}\text { Cup and plating } \\
\text { Various }\end{array}$ & $\begin{array}{l}8 \text {-acute } \\
62- \\
\text { chronic }\end{array}$ & $\begin{array}{l}100 \\
\mathrm{NR}\end{array}$ & $\begin{array}{l}\mathrm{NR} \\
\mathrm{NR}\end{array}$ & $\begin{array}{c}0 \\
16.1\end{array}$ & $\begin{array}{l}2.8 \\
2.9\end{array}$ \\
\hline $\begin{array}{l}\text { Stiehl et } \\
\mathrm{al}^{17}\end{array}$ & Revision hip & $\begin{array}{l}\text { Bulk allograft, AP } \\
\text { plating }\end{array}$ & 17 & 78 & NR & 47 & 6.9 \\
\hline $\begin{array}{l}\text { Berry et } \\
\text { al }^{16}\end{array}$ & $\begin{array}{l}\text { Severe PD due } \\
\text { to revision hip }\end{array}$ & $\begin{array}{l}\text { Posterior plating } \\
\text { and uncemented } \\
\text { cup/Anti-protrusio } \\
\text { cage and AP } \\
\text { plating. }\end{array}$ & 31 & 71 & $\begin{array}{l}60 \% \text { clinical } \\
\text { satisfactory }\end{array}$ & 33 & 3 \\
\hline $\begin{array}{l}\text { Taunton et } \\
\mathrm{al}^{12}\end{array}$ & $\begin{array}{l}\text { Severe PD due } \\
\text { to revision hip }\end{array}$ & Custom triflange & 57 & 81 & 74.8 & 30 & 5.4 \\
\hline Egglietal $^{11}$ & Revision hip & $\begin{array}{l}\text { Ganz ring, } \mathrm{AP} \\
\text { plating }\end{array}$ & 7 & 100 & 73.1 & 14.3 & 8 \\
\hline $\begin{array}{l}\text { Sporer et } \\
\mathrm{al}^{13}\end{array}$ & Revision hip & $\begin{array}{l}\text { Pelvic distraction } \\
\text { TM cup and } \\
\text { augments }\end{array}$ & 20 & NR & $\begin{array}{c}\text { Mean } \\
\text { postoperativ } \\
\text { e MP score: } \\
6.6\end{array}$ & 5 & 4.5 \\
\hline $\begin{array}{l}\text { Current } \\
\text { study }\end{array}$ & $\begin{array}{l}\text { PD due to } \\
\text { ununited } \\
\text { fracture }\end{array}$ & $\begin{array}{c}\text { Posterior column } \\
\text { plating, } \\
\text { uncemented cup }\end{array}$ & 11 & 100 & 93.1 & 0 & 1.25 \\
\hline
\end{tabular}

\section{Conclusion}

Although this study is preliminary, we conclude that single stage acetabulum reconstruction by posterior column plating with impaction bone grafting and uncemented porous coated hemispherical acetabulum cup hip arthroplasty is a reliable option in management of pelvic discontinuity caused by ununited fracture of acetabulum.

\section{Conflict of Interest: None}

\section{References}

1. Letournel E. Diagnosis and treatment of nonunions and malunions of acetabular fractures. Orthop Clin North Am. 1990;21(4):769-788.

2. Mears, D.C., Velyvis, J.H., Chang C.P. Displaced acetabular fractures managed operatively: indicators of outcome. Clin Orthop Relat Res. 2003;407:173-186.

3. Dilogo IH, Tobing JFL. Neglected acetabular fracture: Fix or replace? J Clin Orthop \& Trauma. 2017;8:S3-S10.

4. Amol Chitre, Henry Wynn Jones, Nikhil Shah, and Anthony Clayson. Complications of total hip arthroplasty: periprosthetic fractures of the acetabulum. Curr Rev Musculoskelet Med. 2013;6(4):357-363.

5. Andrew J. Marcantonio, Richard Iorio, Lawrence M. Specht, Michael S. Kain. Acute total hip replacement combined with open reduction internal fixation (ORIF) for the management of acetabular fracture in the elderly. Operative Techniques in Orthopaedics, 2011;21(4):293297.

6. Matta JM, Ferguson TA. Total hip replacement after acetabular fracture. Orthopaedics. 2005;28(9):959-960.

7. Anglen JO, Burd TA, Hendricks KJ, Harrison P. The "Gull Sign": a harbinger of failure for internal fixation of geriatric acetabular fractures. J Orthop Trauma. 2003; 17:625-634.

8. Desai G, Ries MD. Early postoperative acetabular discontinuity after total hip arthroplasty. $J$ Arthroplasty. 2011;26(8):e17-e19.

9. Rogers BA, Whittingham-Jones PM, Mitchell PA, Safir OA, Bircher MD, Gross AE. The reconstruction of periprosthetic pelvic discontinuity. $J$ Arthroplasty. 2012;27:1499-1506

10. Amenabar T, Rahman WA, Hetaimish BM, Kuzyk PR, Safir OA, Gross AE. Promising mid-term results with a cup-cage construct for large acetabular defects and pelvic discontinuity. Clin Orthop Relat Res. 2016;474(2):408414.

11. Eggli S, Muller C, Ganz R. Revision surgery in pelvic discontinuity: an analysis of seven patients. Clin Orthop Relat Res. 2002;398:136-45. 
12. Taunton MJ, Fehring TK, Edwards P, Bernasek T, Holt GE, Christie MJ. Pelvic discontinuity treated with custom triflange component: a reliable option. Clin Orthop Relat Res. 2012;470:428-434.

13. Sporer SM, Bottros JJ, Hulst JB, Kancherla VK, Moric M, Paprosky WG. Acetabular distraction: An alternative for severe defects with chronic pelvic discontinuity? Clin Orthop Relat Res. 2012;470(11):3156-3163.

14. Schreurs BW, Zengerink M, Welten ML, van Kampen A, Slooff TJ. Bone impaction grafting and a cemented cup after acetabular fracture at 3-18 years. Clin Orthop Relat Res. 2005;437:145-151.

15. Ullmark G. Bigger size and defatting of bone chips will increase cup stability. Arch Orthop Trauma Surg. 2000;120:445-457.
16. Berry DJ, Lewallen DG, Hanssen AD, Cabanela ME: Pelvic discontinuity in revision total hip arthroplasty. $J$ Bone Joint Surg Am. 1999;81(12):1692-1702.

17. Stiehl JB, Saluja R, Diener T: Reconstruction of major column defects and pelvic discontinuity in revision total hip arthroplasty. J Arthroplasty. 2000;15(7):849-857.

How to cite this article: Kumar D, Kushwaha N. S, Jaiswal Y, Singh A, Sharma V. Results of singlestage acetabulum reconstruction and total hip arthroplasty in the management of pelvic discontinuity caused by ununited acetabulum fracture. Indian J Orthop Surg. 2018;4(4):368-374. 